\title{
Modeling and Simulation of Piezoelectric Devices
}

\author{
Dorina Popovici, Florin Constantinescu, Mihai Maricaru, \\ Florea Ioan Hantila, Miruna Nitescu and Alexandru Gheorghe \\ Politehnica University of Bucharest \\ Romania
}

\section{Introduction}

The piezoelectric effect occurs in materials for which an externally applied elastic strain causes a change in electric polarization which produces a charge and a voltage across the material. The converse piezoelectric effect is produced by an externally applied electric field, which changes the electric polarization, which in turn produces an elastic strain.

The most known piezoelectric material is quartz crystal. Many other natural crystalline solids, as Rochelle salt, ammonium dihydrogen phosphate, lithium sulfate, and tourmaline as well as some man-made crystal as gallium orthophosphate, aluminium nitride (AIN), and langasite exhibit piezoelectric properties. A lot of artificial ceramics as barium titanate, lead titanate, lead zirconate titanate (PZT), potassium niobate, lithium niobate, and lithium tantalite have similar properties.

The most known technical application is the piezoelectric transducer. In the last years electromechanical AIN resonators emerged as a very efficient solution for mobile communications filters due to the possibility to be integrated at a relatively low cost together with CMOS circuits in systems on a chip and systems in a package.

In most applications the piezoelectric devices have a linear behaviour. In Section 2 the linear and nonlinear equations of the piezoelectric effect are described, a new iterative procedure for solving the nonlinear equations is given, and some aspects of the Finite Element solution are discussed. An electromechanical field analysis of a displacement transducer is presented in Section 3. Sections 4 and 5 show some recent applications in the mobile communication technology. The field analysis of a bulk acoustic wave (BAW) resonator using 3D linear models is presented in Section 4. Some nonlinear effects in power BAW resonators together with their circuit models are discussed in Section 5.

\section{Electromechanical field equations of piezoelectric devices}

\subsection{Linear behaviour}

In the case of linear behaviour (Cady, 1964; Wilson, 1989), the equations giving the 
displacement $\mathbf{u}$, the stress $\overline{\bar{t}}$ and the electric potential $V$ are ${ }^{1}$ :

$$
\begin{gathered}
\nabla \cdot \overline{\bar{t}}-\mathbf{f}_{f}-\rho \ddot{\mathbf{u}}=\mathbf{f} \\
-\nabla \cdot \bar{\varepsilon} \nabla V+\nabla \cdot \mathbf{P}_{M}=0
\end{gathered}
$$

where:

- $\quad \overline{\bar{\varepsilon}}$ is the dielectric permittivity tensor.

- $\mathbf{f}$ is the external force.

The friction force is:

$$
\mathbf{f}_{f}=\eta \dot{\mathbf{u}}
$$

- The stress tensor $\overline{\bar{t}}$ has two components: $\overline{\bar{t}}=\overline{\bar{t}}_{M}+\overline{\bar{t}}_{E}$

- The mechanical stress tensor depends on the strain tensor $\bar{s}$ :

$$
\overline{\bar{t}}_{M}=\hat{c}\left(\nabla_{s} \mathbf{u}\right)=\hat{c} S
$$

where $\hat{c}$ is the elastic stiffness matrix evaluated for constant electric field intensity, $\mathrm{E}=-\nabla V$ and $\nabla_{s} \mathbf{u}=\frac{1}{2}\left[(\nabla \mathbf{u})+(\nabla \mathbf{u})^{T}\right]$ (the superscript $T$ denotes the transpose of the matrix).

- The piezoelectric stress tensor depends on the electric field intensity:

$$
\overline{\bar{t}}_{E}=\hat{e}^{T}(\nabla V)
$$

where $\hat{e}$ is the piezoelectric matrix.

- The component of the polarization due to the strain is:

$$
\mathbf{P}_{M}=\hat{e} \hat{S}=\hat{e}\left(\nabla_{s} \mathbf{u}\right)
$$

Using (3),(4),(5),(6), equations (1) and (2) become:

$$
\begin{gathered}
\nabla \cdot \hat{c}\left(\nabla_{s} \mathbf{u}\right)+\nabla \cdot \hat{e}^{T}(\nabla V)-\eta \dot{\mathbf{u}}-\rho \ddot{\mathbf{u}}=\mathbf{f} \\
\nabla \cdot \varepsilon \nabla V-\nabla \cdot \hat{e}\left(\nabla_{s} \mathbf{u}\right)=0
\end{gathered}
$$

For equations (2) and (8) we consider the static regime of the electric field. In order to have a unique solution, mechanical and electrical boundary conditions must be added: $\mathbf{u}=0$, for clamped surfaces, $\mathbf{n} \bar{t}=0$, for free surfaces, a hybrid boundary condition (BC) in the case of a very light movable electrode; $V=$ imposed for electrodes, $\mathbf{n} \cdot \mathbf{D}=0$ for field surfaces or symmetry surfaces, where:

$$
\mathbf{D}=-\overline{\bar{\varepsilon}} \nabla V+\mathbf{P}_{M}
$$

\footnotetext{
1 Notations: the boldface letters represent vectors, tensors are represented as $\overline{\bar{t}}, \nabla \mathbf{u}$ is a diadic product, while $\nabla \cdot \mathbf{u}$ is a scalar product and a dot above a variable denotes a time derivative..
} 
The friction forces are neglected for modal analysis. Equations (7) and (8) become:

$$
\begin{gathered}
\nabla \cdot \hat{c}\left(\nabla_{s} \mathbf{u}\right)+\nabla \cdot \hat{e}^{T}(\nabla V)+\omega^{2} \rho \mathbf{u}=\mathbf{0} \\
\nabla \cdot \varepsilon \nabla V-\nabla \cdot \hat{e}\left(\nabla_{s} \mathbf{u}\right)=0
\end{gathered}
$$

The values $\omega_{k}$ which allow nontrivial solutions $\mathbf{u}_{k}$ of equations (10),(11) give resonance frequencies.

\subsection{Nonlinear constitutive equations}

The nonlinear behaviour can be modelled using the nonlinear constitutive equations:

1. The friction force depends nonlinearly on the velocity (time derivative of displacement):

$$
\mathbf{f}_{f}=F(\dot{\mathbf{u}})
$$

2. The relationship $\overline{\bar{t}}-\bar{s}$ is nonlinear. This is possible in the case of large strains (powerful stress). The dielectric may be destroyed and the durability decreases. Hence, this case must be avoided.

3. The relationship D-E is nonlinear:

$$
\mathbf{D}=\mathrm{D}(-\nabla V)+\mathbf{P}_{M}
$$

We do not know yet results which present this kind of relationship.

4. The relationships of the piezoelectric effects are nonlinear:

$$
\begin{gathered}
\overline{\bar{t}}=\mathrm{T}(\mathrm{E}) \\
\mathbf{P}_{M}=\mathrm{P}(\overline{\bar{s}})
\end{gathered}
$$

If the complementary energy may be defined:

$$
\delta U^{*}=\sum_{i, j=1}^{3} t_{i j} d s_{i j}-\sum_{k=1}^{3} P_{k} d E_{k}
$$

we have:

$$
\frac{\partial \mathrm{T}_{i j}}{\partial E_{k}}=-\frac{\partial \mathrm{P}_{k}}{\partial s_{i j}}
$$

In the linear case, relationship (17) defines the same matrix $\hat{e}$ in (5) and (6).

\subsection{Iterative Procedures for Nonlinear Materials}

The usual method taking into account the nonlinearity is Newton-Raphson, which is used in most commercial simulators. This method provides a great convergence speed, but in some cases the convergence is not always achieved.

The nonlinearity of the friction force relationship may be treated using the fixed point Picard-Banach procedure. We replace the relation (12) by: 


$$
\mathbf{f}_{f}=\eta \dot{\mathbf{u}}+\mathbf{f}_{r}
$$

where the nonlinearity is contained in:

$$
\mathbf{f}_{r}=F(\dot{\mathbf{u}})-\eta \dot{\mathbf{u}}=G(\dot{\mathbf{u}})
$$

It may be proved (Hantila et al., 2000) that if the function $F$ is uniformly monotonic

$$
(F(\mathbf{a})-F(\mathbf{b})) \cdot(\mathbf{a}-\mathbf{b}) \geq \lambda|\mathbf{a}-\mathbf{b}|^{2}, \lambda>0, \quad \forall \mathbf{a}, \mathbf{b}
$$

and Lipschitzian

$$
|F(\mathbf{a})-F(\mathbf{b})|<\Lambda|\mathbf{a}-\mathbf{b}|, \quad \forall \mathbf{a}, \mathbf{b}
$$

we can find a value for $\eta$ so that the function $G$, defined by (19) is a contraction i.e.

$$
|G(\mathbf{a})-G(\mathbf{b})| \leq \theta|\mathbf{a}-\mathbf{b}|, \quad \theta<1, \quad \forall \mathbf{a}, \mathbf{b}
$$

We propose the following iterative procedure:

a. We choose an arbitrary initial value $\mathbf{f}_{r}^{(0)}$.

b. We compute $\mathbf{u}^{(1)}$ and hence $\dot{\mathbf{u}}^{(1)}$ solving the system (7) and (8), where the force $\mathbf{f}$ is replaced by $\mathbf{f}+\mathbf{f}_{r}^{(0)}$.

c. We correct the force $\mathbf{f}_{r}$ with (19):

$$
f_{r}^{(1)}=G\left(\dot{\mathbf{u}}^{(1)}\right)
$$

The steps b) and c) are repeated until the error

$$
e r^{(n)}=\int_{\Omega 0}^{t} \int_{0} \eta\left(\Delta \dot{\mathbf{u}}^{(n)}\right)^{2} d \tau d \Omega=\left\|\Delta \dot{\mathbf{u}}^{(n)}\right\|_{\eta}^{2}
$$

is small enough, where $\Delta \dot{\mathbf{u}}^{(n)}=\dot{\mathbf{u}}^{(n)}-\dot{\mathbf{u}}^{(n-1)}$.

It may be proved that for a given $\mathbf{f}_{r}$ equations (7) and (8) have a unique solution $\mathbf{u}$, hence $\dot{\mathbf{u}}=W\left(\mathbf{f}_{r}\right)$ and the function $W$ is non-expansive:

$$
|W(\mathbf{a})-W(\mathbf{b})| \leq|\mathbf{a}-\mathbf{b}|, \quad \forall \mathbf{a}, \mathbf{b}
$$

Therefore, the above procedure gives the Picard-Banach convergent sequence of the contraction $\mathrm{GW}$, where the function $\mathrm{G}: L^{2}([0, t] \times \Omega) \rightarrow L^{2}([0, t] \times \Omega)$ is defined by the local function $G$. The procedure has several important advantages: we may evaluate the errors with respect to the exact solution, the overrelaxation may be applied, the system matrix of the numerical form of equations (7), (8) is the same at each iteration.

The most convenient procedure for space discretization of equations (7), (8) is the finite element method (see (Makkonen et al., 2001), for instance). The spectral decomposition is recommended for time discretization. 


\subsection{FEM solution of the coupled electromechanical field problem}

In Finite Element Method (FEM), the complete problem domain is discretized. This implies that FEM encounters inherent difficulties in dealing with open boundary field problems, as the problem domain needs to be truncated to keep the size finite. Truncation inevitably introduces an artificial boundary and, consequently, a modelling error resulting from an approximation of the $\mathrm{BC}$ on this boundary. Considering acoustic waves, the truncation of the model causes reflections of the wave on the artificial boundaries (see Fig. 1).

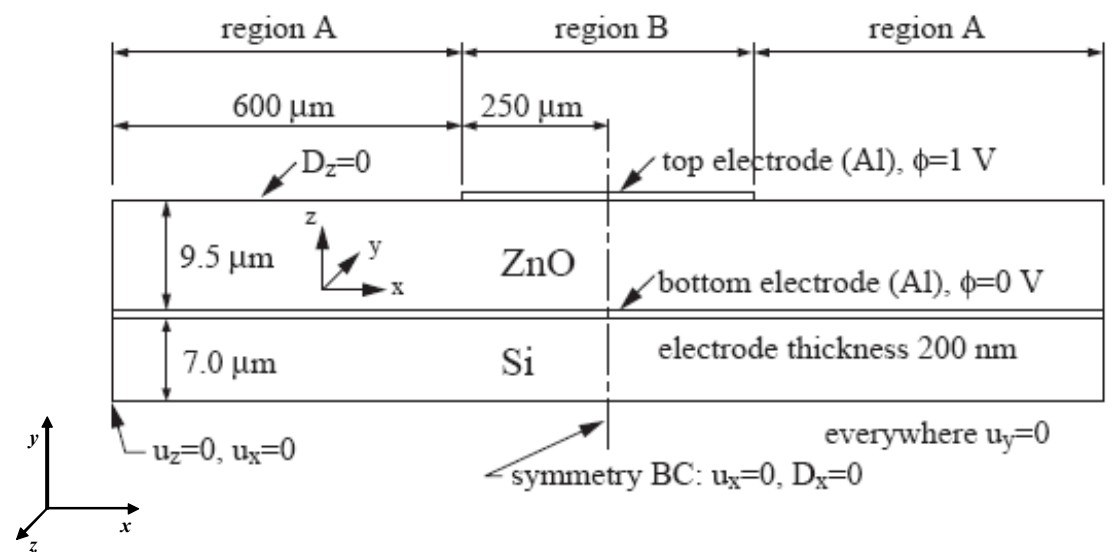

Figure 1. Cross section of a membrane-type composite thin-film BAW resonator showing the boundary conditions imposed in the FEM model

Placing infinite elements along the artificial boundary on the side of the continuum has been suggested as a solution to this problem. The infinite elements strive to implement an ideal absorbing boundary condition, such that a wave incident on the boundary would not reflect back. Instead of infinite elements, one may simply introduce regions at the boundaries of the model where the attenuation of the material increases from zero to a given finite value. Since the increase of the attenuation is gradual, there is no abrupt change in the materials properties which would give rise to reflections of the wave. With a sufficiently high attenuation, the amplitude of the wave entering the region will decay rapidly such that there is no reflection. This solution has the benefit that it can be readily applied without any need for special FEM elements (Makkonen, 2005).

A possible solution is to combine FEM with another method which is used to model the semi-infinite region. An example of such a modelling technique is the FEM/boundaryelement-method (BEM) formalism, which is used in the modelling of surface-acoustic wave devices.

The electromechanical constitutive equations for linear material behaviour that FEM softwares solve are:

$$
\begin{aligned}
& \mathbf{T}=c_{E} \mathbf{S}-e \mathbf{E} \\
& \mathbf{D}=e^{T} \mathbf{S}+\varepsilon_{S} \mathbf{E}
\end{aligned}
$$

where: $\mathbf{T}$ is the stress vector (referred to as o elsewhere); $\mathbf{D}$ is the electric flux density vector; $\mathbf{S}$ is the strain vector (referred to as $\varepsilon$ elsewhere); $\mathbf{E}$ is the electric field vector; $c_{\mathrm{E}}$ is the 
elasticity matrix (evaluated at constant electric field); $e$ is piezoelectric stress matrix, and $\varepsilon_{\mathrm{S}}$ is the dielectric matrix (evaluated at constant mechanical strain).

The elasticity matrix $c$ can be given directly in uninverted form [c] as a general anisotropic symmetric matrix:

$$
c_{E}=\left[\begin{array}{cccccc}
c_{11} & c_{12} & c_{13} & c_{14} & c_{15} & c_{16} \\
& c_{22} & c_{23} & c_{24} & c_{25} & c_{26} \\
& & c_{33} & c_{34} & c_{35} & c_{36} \\
& & & c_{44} & c_{45} & c_{46} \\
\text { symmetric } & & c_{55} & c_{56} \\
& & & & & c_{66}
\end{array}\right]
$$

The input can also be $c_{\mathrm{D}}$, the elasticity matrix (evaluated at constant electric flux density):

$$
c_{D}=c_{E}+\frac{e^{2}}{\varepsilon_{S}}
$$

The piezoelectric stress matrix $e$ relates the electric field vector $\mathbf{E}$ in the order $x, y, z$ to the stress vector $\mathbf{T}$ in the order $x, y, z, x y, y z, x z$ and has the form:

$$
e=\left[\begin{array}{lll}
e_{11} & e_{12} & e_{13} \\
e_{21} & e_{22} & e_{23} \\
e_{31} & e_{32} & e_{33} \\
e_{41} & e_{42} & e_{43} \\
e_{51} & e_{52} & e_{53} \\
e_{61} & e_{62} & e_{63}
\end{array}\right]
$$

The piezoelectric matrix can also be given as a piezoelectric strain matrix $d$. The piezoelectric strain matrix $d$ can be converted to the piezoelectric stress matrix $e$ using the elasticity matrix c:

$$
e=c \cdot d
$$

The dielectric matrix $\varepsilon_{S}$ uses the electrical permittivities and can be described in orthotropic or anisotropic form:

$$
\varepsilon_{S}=\left[\begin{array}{ccc}
\varepsilon_{11} & 0 & 0 \\
0 & \varepsilon_{22} & 0 \\
0 & 0 & \varepsilon_{33}
\end{array}\right] \text { or } \varepsilon_{S}=\left[\begin{array}{ccc}
\varepsilon_{11} & \varepsilon_{12} & \varepsilon_{13} \\
& \varepsilon_{22} & \varepsilon_{23} \\
\text { symmetric } & & \varepsilon_{33}
\end{array}\right]
$$

The dielectric matrix can also be given as a dielectric permittivity matrix at constant stress $\varepsilon_{T}$. We can convert the dielectric matrix at constant stress to the dielectric matrix at constant strain:

$$
\varepsilon_{S}=\varepsilon_{T}-e^{T} d
$$


The finite element discretization is performed by establishing nodal solution variables and element shape functions over an element domain which approximates the solution.

$$
\begin{aligned}
u_{c} & =N_{u}^{T} \cdot u \\
V_{c} & =N_{V} \cdot V
\end{aligned}
$$

where: $u_{c}$ is the displacement within element domain in the $\mathrm{x}, \mathrm{y}, \mathrm{z}$ directions; $V_{c}$ is the electrical potential within element domain; $N_{u}$ is the matrix of displacement shape functions; $N_{V}$ is the vector of electrical potential shape function; $u$ is the vector of nodal displacements, and $V$ is the vector of nodal electrical potential.

Then the strain $\mathbf{S}$ and electric field $\mathbf{E}$ are related to the displacements and potentials, respectively, as:

$$
\begin{gathered}
\mathbf{S}=B_{u} \cdot u \\
\mathbf{E}=-B_{V} \cdot V \\
B_{u}=\left[\begin{array}{cccccc}
\frac{\partial}{\partial x} & 0 & 0 & \frac{\partial}{\partial y} & 0 & \frac{\partial}{\partial z} \\
0 & \frac{\partial}{\partial y} & 0 & \frac{\partial}{\partial x} & \frac{\partial}{\partial z} & 0 \\
0 & 0 & \frac{\partial}{\partial z} & 0 & \frac{\partial}{\partial y} & \frac{\partial}{\partial x}
\end{array}\right]^{T} \\
B_{V}=\left[\begin{array}{llll}
\frac{\partial}{\partial x} & \frac{\partial}{\partial y} & \frac{\partial}{\partial z}
\end{array}\right]^{T}
\end{gathered}
$$

After the application of the variational principle and finite element discretization, the coupled finite element matrix equation is:

$$
\left[\begin{array}{cc}
M & 0 \\
0 & 0
\end{array}\right]\left[\begin{array}{c}
\ddot{u} \\
\ddot{V}
\end{array}\right]+\left[\begin{array}{cc}
C & 0 \\
0 & 0
\end{array}\right]\left[\begin{array}{c}
\dot{u} \\
\dot{V}
\end{array}\right]+\left[\begin{array}{cc}
K & K_{z} \\
K_{z}^{T} & K_{d}
\end{array}\right]\left[\begin{array}{c}
u \\
V
\end{array}\right]=\left[\begin{array}{c}
F \\
L
\end{array}\right]
$$

The following equations provide an explanation of the submatrices in (39).

Structural mass ( $\rho$ is the mass density):

$$
M=\int_{\text {element }} \rho N_{u} N_{u}^{T} d v
$$

The damping matrix $(C)$ may be used in harmonic, damped modal and transient analyses as well as substructure generation. In its most general form, it is:

$$
M=\alpha M+\left(\beta+\beta_{c}\right) K+\sum_{j=1}^{N_{m}}\left[\left(\beta_{j}^{m}+\frac{2}{\Omega} \beta_{j}^{\xi}\right) K_{j}\right]+\sum_{k=1}^{N_{e}} C_{k}+C_{\xi}
$$


where: $C$ is the structure damping matrix; $a$ is the mass matrix multiplier; $M$ is the structure mass matrix; $\beta$ is the stiffness matrix multiplier; $\beta_{c}$ is the variable stiffness matrix multiplier; $K$ is the structure stiffness matrix; $N_{m}$ is the number of materials with $\beta_{j}^{m}$ (stiffness matrix multiplier for material $\mathrm{j}$ ), $\beta_{j}^{\xi}$ ( constant (frequency-independent) stiffness matrix coefficient for material j, $\Omega$ - circular excitation frequency) and $K_{j}$ the portion of structure stiffness matrix based on material $\mathrm{j} ; N_{e}$ is the number of elements with specified damping $\left(C_{k}-\right.$ element damping matrix, $C_{\xi}$ - frequency-dependent damping matrix).

Structural stiffness:

$$
K=\int_{\text {element }} B_{u}^{T} c B_{u} d v
$$

Dielectric conductivity:

$$
K_{d}=-\int_{\text {element }} B_{V}^{T} \varepsilon B_{V} d v
$$

Piezoelectric coupling matrix:

$$
K_{z}=-\int_{\text {element }} B_{u}^{T} e B_{V} d v
$$

Structural load vector, $F$, is a vector of nodal forces, surface forces, and body forces. Electrical load vector, $L$, is a vector of nodal, surface, and body charges.

In a FEM mesh, each node point is connected only to a limited number of other nearby located nodes. The benefit of this local connectivity is that the FEM matrices (system matrices) which describe the complete modelled system have a band structure. The relevant system matrices are the electromechanical stiffness matrix $\mathrm{K}$ and mass matrix $\mathrm{M}$. In each node point of the FEM mesh, at least four field variables are considered (i.e., the three components of displacement and the electric potential). The values of the fields at a node point are the unknowns or degrees of freedom (DOFs) which are finally computed from the FEM equations.

In the modal analysis, the eigenproblem resulting from the FEM formulation is solved for the frequencies of the vibration modes (eigenfrequencies) and for their mode shapes (eigenvectors).

FEM software can also solve the field problem, where the response of the structure to time harmonic loading is computed. In harmonic analysis, the damping can be taken into account, since a solver for complex-valued linear systems of equations can be included into the FEM software.

Starting from coupled electroelastic equations (Ostergaard \& Pawlak, 1986) four types of solutions are possible:

- Static Analysis (inertial and damping effects are ignored except static acceleration effects such as gravity; displacements and/or electric potentials are obtained).

- Mode-Frequency Analysis (mode shapes and natural frequencies may be obtained).

- Harmonic Analysis (the investigation of a piezoelectric structure under the influence of harmonic forces, currents, displacements, and/or voltages; system response characteristics to harmonic loads are obtained). 
- Transient Analysis (the investigation of a piezoelectric structure under the influence of time-dependent forces, currents, displacements, and/or voltages; transient response of the system is computed).

\section{Field analysis of a displacement transducer}

The FEM analysis of a cantilever beam deformation producing electrical voltages trough a direct piezoelectric effect is described in the following (Dorina Popovici et al., 2006).

\subsection{Geometry of the model}

To simulate the structure we have chosen a multiphysics problem: plane stress and piezo plane stress. The geometry used is presented in figure below:

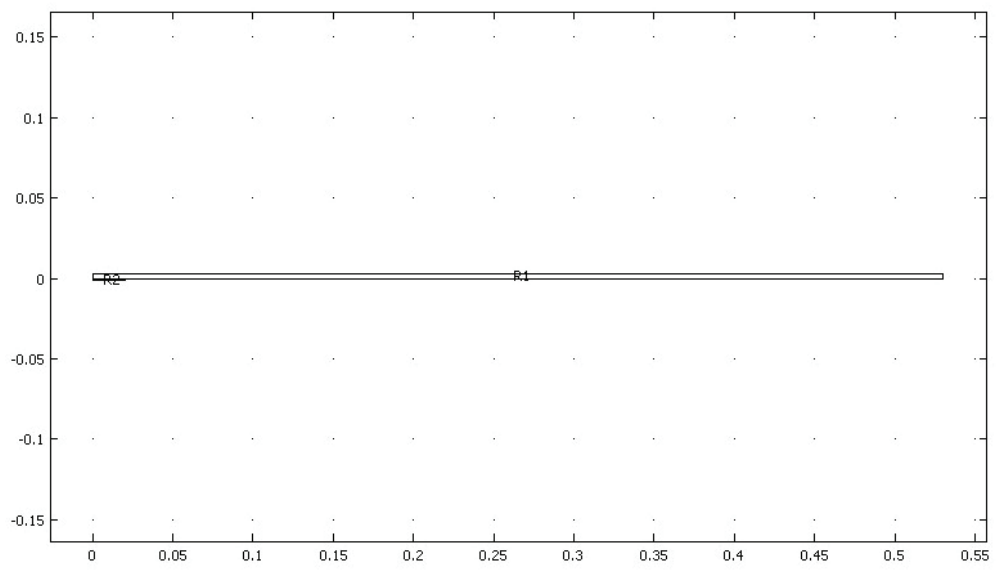

Figure 2. The geometry of the problem

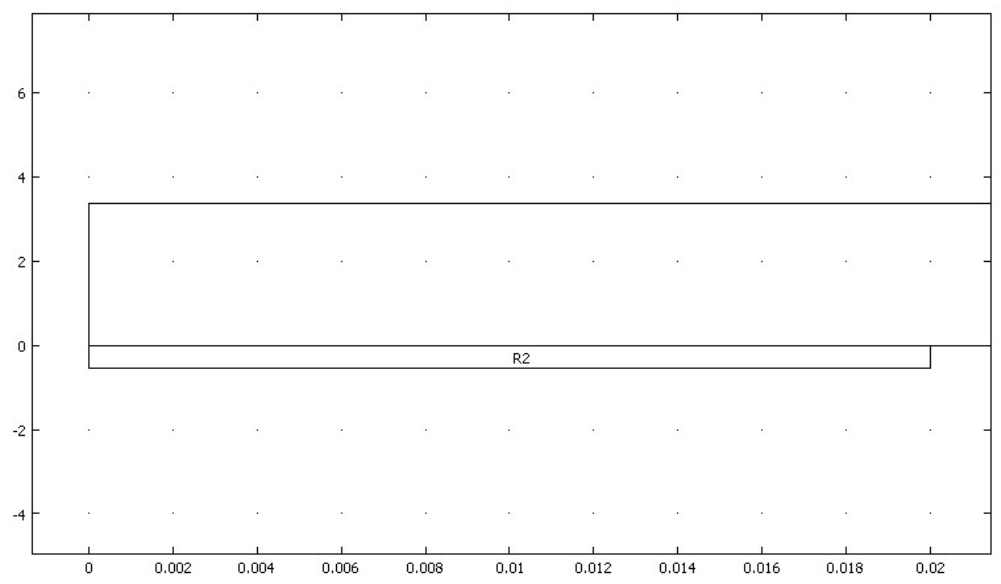

Figure 3. Zoom in the PZT cell section 
The domain R1 is an isotropic structural steel beam with a length of $550 \mathrm{~mm}$, width of 50 $\mathrm{mm}$ and thickness of $5 \mathrm{~mm}$. This material is defined in Library 1 of (COMSOL, 2005). The domain R2 is the PZT 5H cell which has a length of $20 \mathrm{~mm}$, width of $50 \mathrm{~mm}$ and thickness of $0,5 \mathrm{~mm}$.

For the structural steel we used the following material constants $\mathrm{E}=2 \cdot 10^{5}[\mathrm{MPa}]$, Poisson's ratio $v=0.33$ and density $\rho=7850 \mathrm{~kg} / \mathrm{m}^{3}$.

The PZT $-5 \mathrm{H}$ properties are those listed in (COMSOL, 2005): $c_{E}\left(c_{11}=c_{22}=126, c_{12}=80.5\right.$, $\mathrm{c}_{13}=\mathrm{c}_{23}=126, \mathrm{c}_{33}=117, \mathrm{c}_{44}=23.3, \mathrm{c}_{55}=\mathrm{c}_{66}=23$, all in GPa $), e\left(\mathrm{e}_{51}=\mathrm{e}_{42}=17, \mathrm{e}_{13}=\mathrm{e}_{23}=17, \mathrm{e}_{33}=23.3\right.$, $\left.\left[\mathrm{C} / \mathrm{m}^{2}\right]\right), \varepsilon_{S}\left(\varepsilon_{11}=\varepsilon_{22}=1704, \varepsilon_{33}=1433\right.$, relative values $)$.

The boundary conditions resulted from the working conditions. For the mechanical part of the problem a constraint of zero displacement on the left side of the beam and the PZT cell has been considered. The load was applied on the right end of the beam only on the $y$ direction.
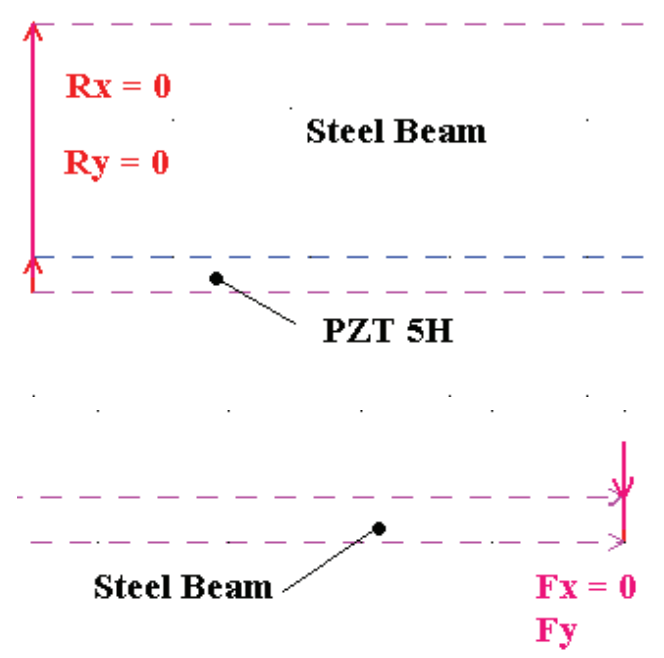

Figure 4. The mechanical boundary conditions

We set the horizontal bottom surface of the PZT cell to ground and a zero charge/symmetry condition was considered on the top surface.

The meshed model contains 3516 triangular elements.

\subsection{Results}

Three basic analysis types available in the Structural Mechanics Module have been considered:

- Static

- Eigenfrequency

- Transient.

At first, a statical analysis has been made, where a uniform distributed load has been applied at the right end of the beam. This force has only a vertical component $f_{y}=10000$ 
$\mathrm{N} / \mathrm{m}$. The stationary direct linear solver UMFPACK has been used. In Fig. 5, 6, 7 are represented the displacements along the $y$ axis, the maximum displacement at the end of the beam, and the local voltage along the PZT cell.

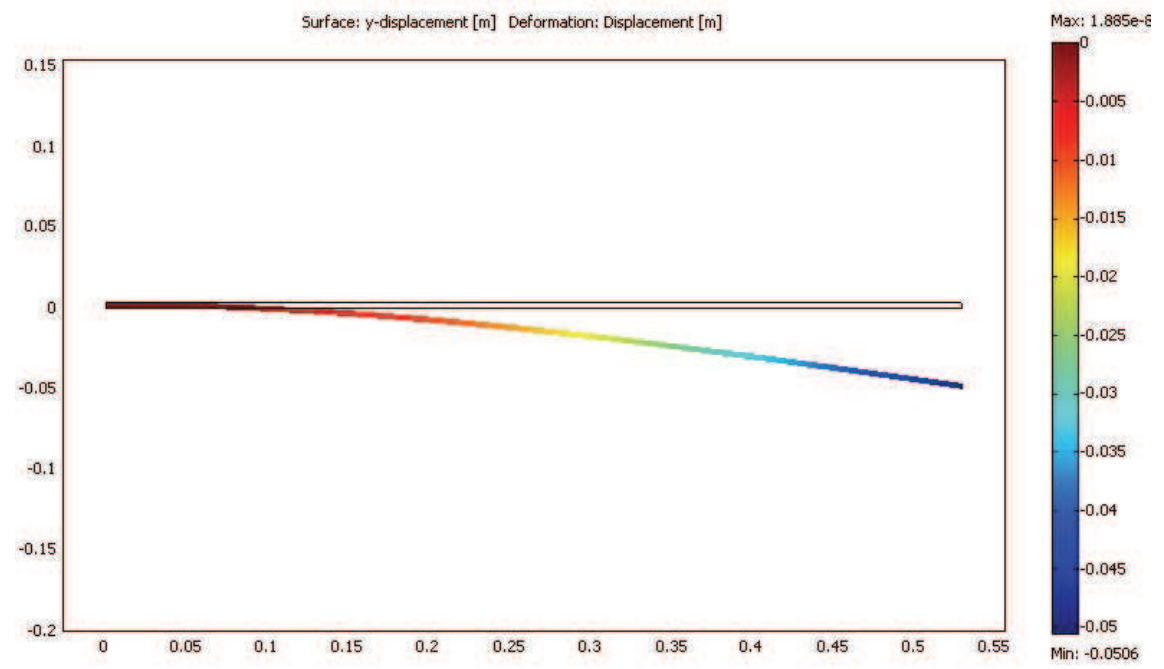

Figure 5. Displacement of the beam on the y axis for $\mathrm{f}_{\mathrm{y}}=10000[\mathrm{~N} / \mathrm{m}]$

The maximum stress calculated with Von Mises criteria has been determined in the left side of the beam (in the vicinity of the clamping side) and was equal to 294 [MPa] and the minimum value in the right side of the beam 0,168 [MPa].

The voltage response of the PZT cell at different loads $\left(f_{\mathrm{y}} \in\{500,1000,2500,5000,7500\right.$, $10000\}[\mathrm{N} / \mathrm{m}]$ ) has a linear variation as we can see in Fig. 8. For the same loads we determined the displacement on y axis of the right side of the beam (Fig. 9) and the maximum stress values (Fig. 10) which has the same linear variation.

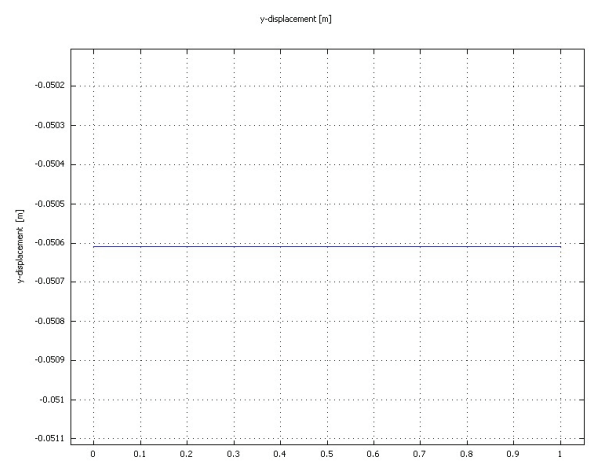

Figure 6. $y$-displacement of the right end of the beam vs. relative position on $\mathrm{z}$ 


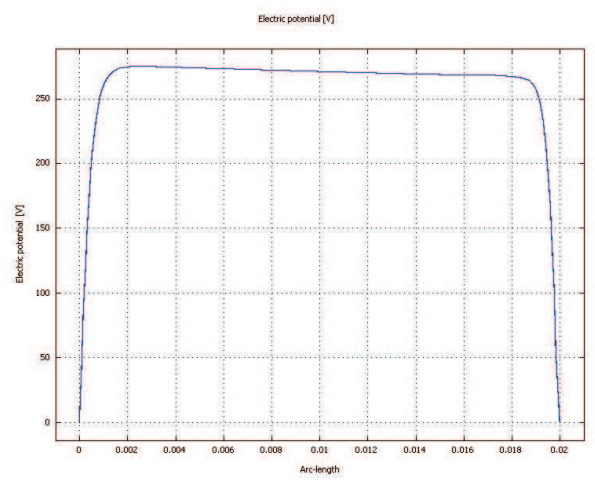

Figure 7. Local voltage vs. longitudinal position along PZT cell

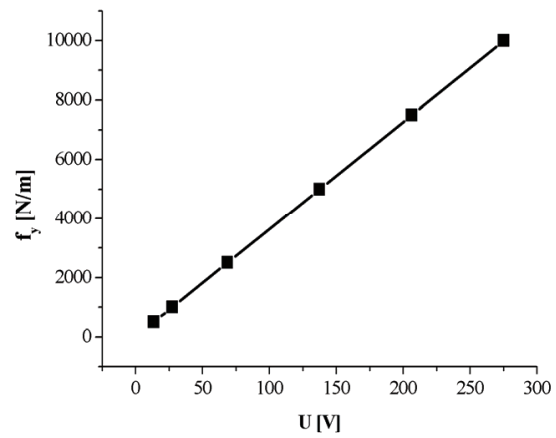

Figure 8 . The linear dependence $\mathrm{F}(\mathrm{U})$

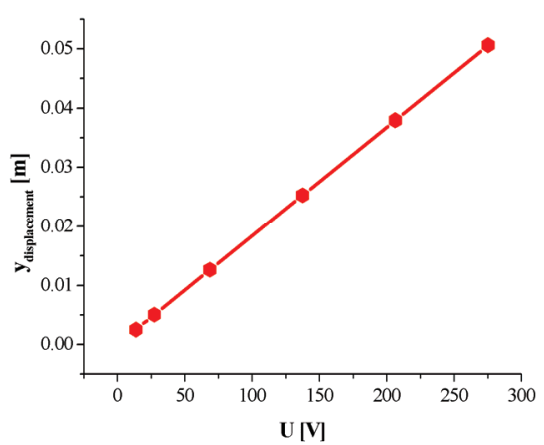

Figure 9. Displacement of the right end of the beam 


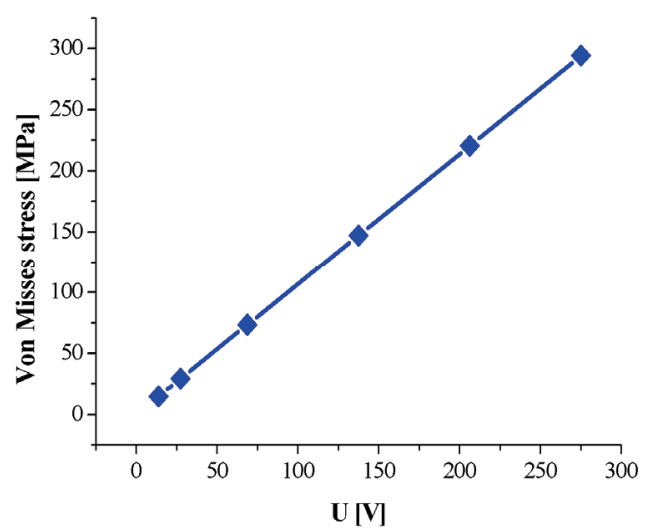

Figure 10. The maximum stress values

The simulation results used to draw figures 8 to 10 are given in Table 1 .

\begin{tabular}{|c|c|c|c|}
\hline $\mathbf{f}_{\mathbf{y}}[\mathbf{N} / \mathbf{m}]$ & $\begin{array}{c}\text { Von Misses } \\
\text { stress [MPa] }\end{array}$ & $\mathbf{y}_{\text {displacement }}[\mathbf{m m}]$ & $\mathbf{U}[\mathbf{V}]$ \\
\hline 500 & 14.71 & 2.53 & 13.75 \\
\hline 1000 & 29.42 & 5.06 & 27.51 \\
\hline 2500 & 73.55 & 12.65 & 68.77 \\
\hline 5000 & 147.1 & 25.30 & 137.55 \\
\hline 7500 & 220.6 & 37.95 & 206.33 \\
\hline 10000 & 294.2 & 50.61 & 275.10 \\
\hline
\end{tabular}

Table 1. Values determined in statical analysis

An eigenfrequency analysis finds the eigenfrequencies and modes of deformation of the analyzed structure. The eigenfrequencies $f$ in the structural mechanics field are related to the eigenvalues $\lambda$ returned by the solvers through:

$$
f=\frac{\sqrt{\lambda}}{2 \pi}
$$

The purpose of the eigenfrequency analysis is to find the six lowest eigenfrequencies and their corresponding shape modes. This model uses the same material, load and constraints as the statical analysis. A direct system solver Umfpack was used and the results are presented below:

\begin{tabular}{|c|c|c|c|c|c|}
\hline $\mathrm{f}_{1}$ & $\mathrm{f}_{2}$ & $\mathrm{f}_{3}$ & $\mathrm{f}_{4}$ & $\mathrm{f}_{5}$ & $\mathrm{f}_{6}$ \\
\hline $9.98 \mathrm{~Hz}$ & $64.48 \mathrm{~Hz}$ & $174.73 \mathrm{~Hz}$ & $341.91 \mathrm{~Hz}$ & $564.31 \mathrm{~Hz}$ & $841.75 \mathrm{~Hz}$ \\
\hline
\end{tabular}

Table 2. The first six eigenfrequencies of the model

A transient analysis giving the displacements and velocities as functions of time was used. In this case, loads and boundary conditions are functions of time. The purpose of this analysis was to find the transient response to a harmonic load with the same amplitude as the static load during the first two periods. The excitation frequency has been taken $50 \mathrm{~Hz}$, 
which is between the first and second eigenfrequency found in the eigenfrequencies analysis.

A harmonic load $f_{x}=0$ and $f_{y}=10000 \sin (100 \pi t)[N / m]$ has been used. Damping is very important in transient analysis but difficult to model. The Structural Mechanics Module supports Rayleigh damping, specifying damping parameters proportional to the mass $\left(\mathrm{a}_{d M}\right)$ and stiffness $\left(\beta_{d K}\right)$ in the following way:

$$
C=\alpha_{d M} M+\beta_{d K} K
$$

where $\mathrm{C}$ is the damping matrix, $\mathrm{M}$ is the mass matrix, and $\mathrm{K}$ is the stiffness matrix. The structure has a constant damping ratio of 0.1 . Two frequencies near the excitation frequency $(20 \mathrm{~Hz}$ and $60 \mathrm{~Hz})$ have been considered to calculate the damping parameters, according to the FEMLAB code (COMSOL, 2005): $\alpha_{d M}=18.8491 / \mathrm{s}$ and $\beta_{d K}=3.979 \cdot 10^{-4} \mathrm{~s}$.

The computation used a solver with the time interval [0;0.08][s] within a step of 0.001 , a relative tolerance of 0.05 and an absolute tolerance of $10^{-9}$.

The following waveforms for the displacement on the $\mathrm{x}$ and $\mathrm{y}$ axes are represented in Fig.11 and 12 .

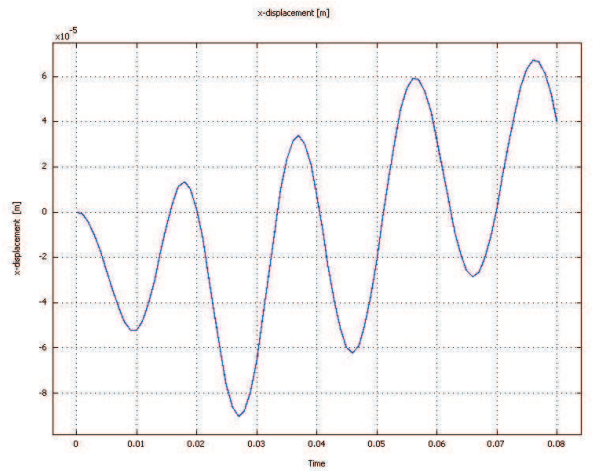

Figure 11. The $\mathrm{x}$ displacement of the right end of the beam

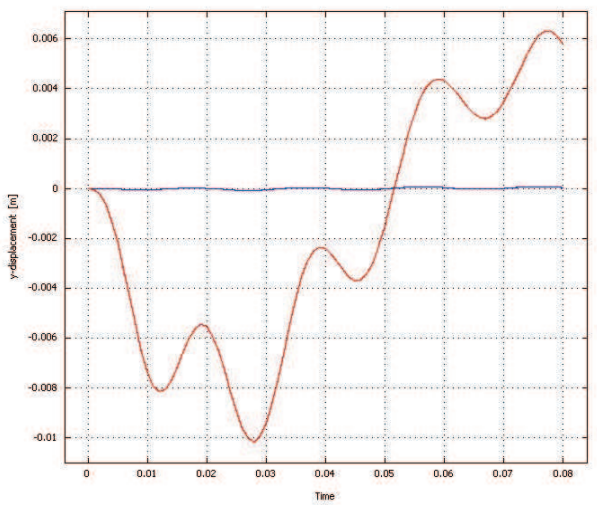

Figure 12. The $\mathrm{x}$ displacement $\left(\_\right.$) and the $\mathrm{y}$ displacement $\left(\_\right)$of the right end of the beam

The voltage output computed on the PZT crystal has a sinusoidal figure with a maximum value of $182.072[\mathrm{~V}]$ and a minimum value of $-150.962 \mathrm{~V}$. 


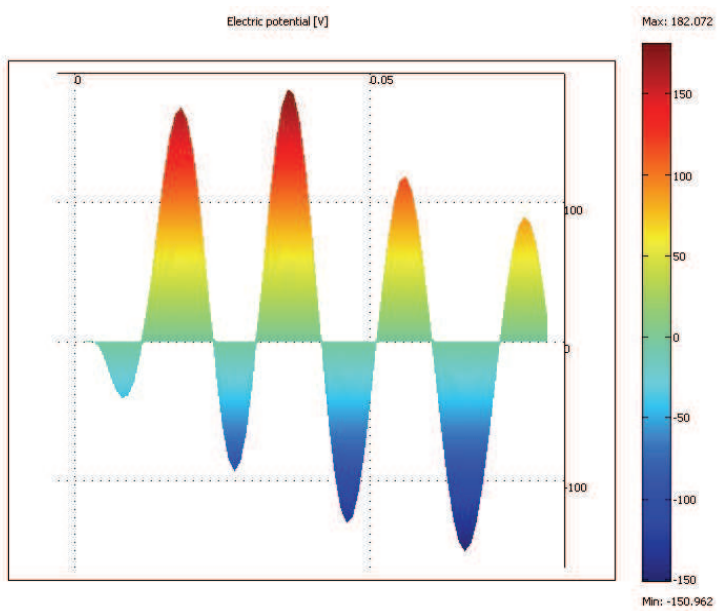

Figure 13. The PZT crystal voltage vs. time

For a more accurate solution the time interval has been increased from 0.08 to 0.2 [s] ; in this case, the total displacement and the equivalent voltage response are represented in Fig.14 and 15 .

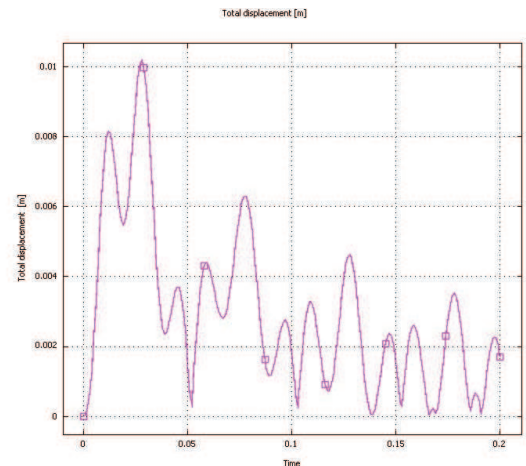

Figure 14. The total displacement of the right side of the beam

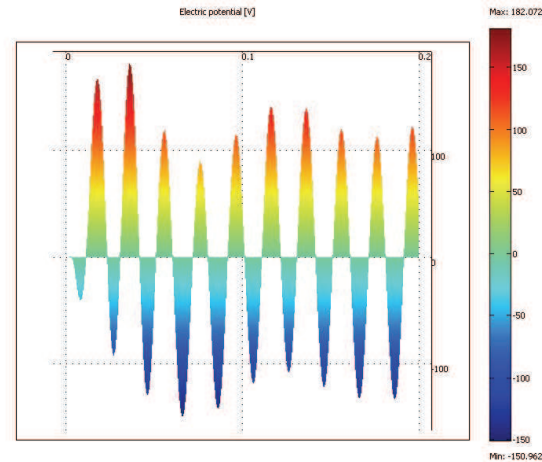

Figure 15. The PZT crystal voltage 


\section{Field analysis of a BAW resonator}

We assume that the cause for material deterioration is the high level of the local stress in resonator layers. It follows that the regions in which material deteriorates correspond to the regions of maximum local stress.

To compute the local stress FEM analysis of a 3D electromechanical field problem must be done. In order to do this, material parameters of various resonator layers must be known. A part of them haven't been measured directly for the case in point, being taken from literature. To verify the parameter values, a model taking into account only longitudinal wave propagation (on $\mathrm{z}$ axis) has been analyzed, the results being reported in paragraph 4.1. Further on, a 3D model of a quarter of a resonator is analyzed in paragraph 4.2.

For piezoelectric analysis (ANSYS, 2005) performs the so called "strong coupling analysis" meaning that the whole equation system of the coupled field problem is used.

4.1 Numerical simulation of longitudinal wave propagation in a BAW resonator structure

\begin{tabular}{|l|l|l|l|l|l|l|}
\hline $\begin{array}{c}\text { Mat. } \\
\text { No. }\end{array}$ & Material & $\begin{array}{c}\text { Density } \rho \\
{\left[\mathrm{kg} / \mathrm{m}^{3}\right]}\end{array}$ & $\begin{array}{c}\text { Longitudinal } \\
\text { velocity }[\mathrm{m} / \mathrm{s}]\end{array}$ & $\begin{array}{c}\mathbf{c}_{33} \\
{[\mathrm{GPa}]}\end{array}$ & $\begin{array}{c}\varepsilon_{33} \\
{[\mathrm{pF} / \mathrm{m}]}\end{array}$ & $\begin{array}{c}\mathbf{e}_{33} \\
{\left[\mathrm{C} / \mathbf{m}^{2}\right]}\end{array}$ \\
\hline 1 & $\mathrm{Mo}$ & 10000 & 6600 & 435.6 & & \\
\hline 3 & $\mathrm{SiOC}$ & 1500 & 2400 & 10.14 & & \\
\hline 4 & $\mathrm{SiN}$ & 2700 & 9300 & 233.523 & & \\
\hline 5 & $\mathrm{Si}$ & 2330 & 8400 & 164.4 & & \\
\hline 6 & $\mathrm{AlN}$ & 3300 & 11000 & 399.3 & 82.6 & 1.5 \\
\hline
\end{tabular}

Table 3. Material properties used for analytical model simulations

\begin{tabular}{|l|l|l|}
\hline $\begin{array}{c}\text { Block } \\
\text { No. }\end{array}$ & $\begin{array}{c}\text { Mat. } \\
\text { No. }\end{array}$ & \multicolumn{1}{|c|}{ Material } \\
\hline 1 & 4 & SiN \\
\hline 3 & 1 & Mo \\
\hline 4 & 6 & AlN \\
\hline 5 & 1 & Mo \\
\hline 6 & 3 & SiOC \\
\hline 7 & 4 & SiN \\
\hline 8 & 3 & SiOC \\
\hline 9 & 4 & SiN \\
\hline 10 & 3 & SiOC \\
\hline 11 & 5 & Si substrate \\
\hline
\end{tabular}

Table 4. List of materials used to fabricate the device 
Additional material properties:

AlN $\quad$ 11=345 GPa, c12=125 GPa, c13=120 GPa, c22= $345 \mathrm{GPa}, \mathrm{c} 23=120 \mathrm{GPa}, \mathrm{c} 33=372.06$ GPa, c44= $118 \mathrm{GPa}, \mathrm{c} 55=110 \mathrm{GPa}, \mathrm{c} 66=110 \mathrm{GPa}$ (each at constant E field) e33=1.5 C/ $\mathrm{m}^{2}$, $\mathrm{e} 13=-0.58 \mathrm{C} / \mathrm{m}^{2}, \mathrm{e} 23=-0.58 \mathrm{C} / \mathrm{m}^{2}$

Si Major Poisson's ratios: $\mathrm{PRXY}=\mathrm{PRYZ}=\mathrm{PRXZ}=0.26$, Young's Modulus $\mathrm{E} x=\mathrm{E} y=\mathrm{Ez}=$ 134.36 GPa

$\underline{\mathrm{SiN}} \quad \mathrm{PRXY}=\mathrm{PRYZ}=\mathrm{PRXZ}=0.29, \mathrm{Ex}=\mathrm{Ey}=\mathrm{Ez}=178.20 \mathrm{GPa}$

$\underline{\mathrm{SiOC}} \quad \mathrm{PRXY}=\mathrm{PRYZ}=\mathrm{PRXZ}=0.22, \mathrm{Ex}=\mathrm{Ey}=\mathrm{Ez}=8.88 \mathrm{GPa}$

$\underline{\mathrm{Mo}} \quad \mathrm{PRXY}=\mathrm{PRYZ}=\mathrm{PRXZ}=0.31, \mathrm{Ex}=\mathrm{Ey}=\mathrm{Ez}=314.26 \mathrm{GPa}$

The resonator has an area of $22500 \mu \mathrm{m}^{2}$.

Other assumptions about the model:

Mechanical boundary conditions: zero displacement constraints for all directions imposed on the bottom surface of the last block (only for stack configuration 10).

Meshing:

- Only one 3-D 20-node brick element is considered in all transversal sections (the transversal waves of propagation are practically neglected).

- $\quad$ Each layer is meshed longitudinally with a number of 3-D 20-node brick elements, that have the height less than $1 / 8$ of the wavelength, and this number is increased until we reach the stability of the resonance and antiresonance frequency values.

This stable solution is reached in general for elements with heights about $1 /(16 \div 25)$ of the wavelength.

Mechanical losses have been taken into account by using a constant damping ratio of $3 \times 10^{-3}$. In this model only longitudinal wave propagation is reproduced. The FEM analysis results have been computed adding layer by layer and are given in the following. The resonance frequencies are compared to those obtained using the Mason multilayer model.

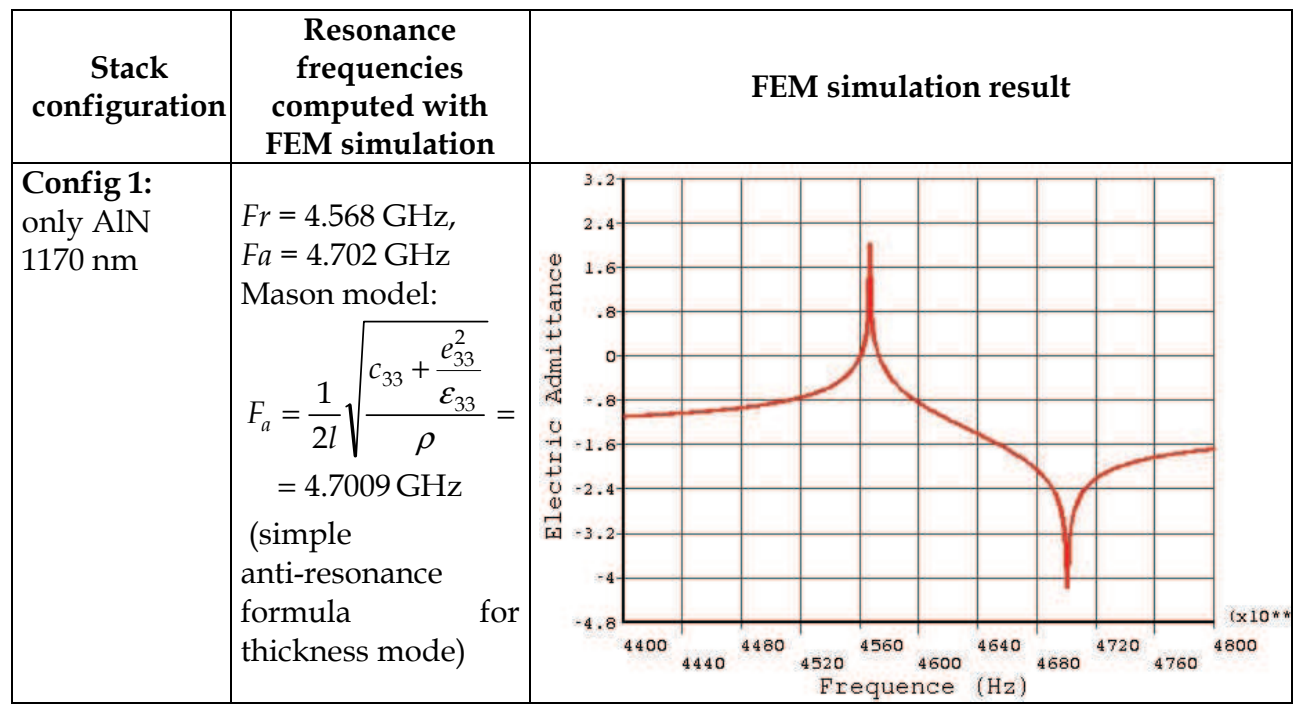




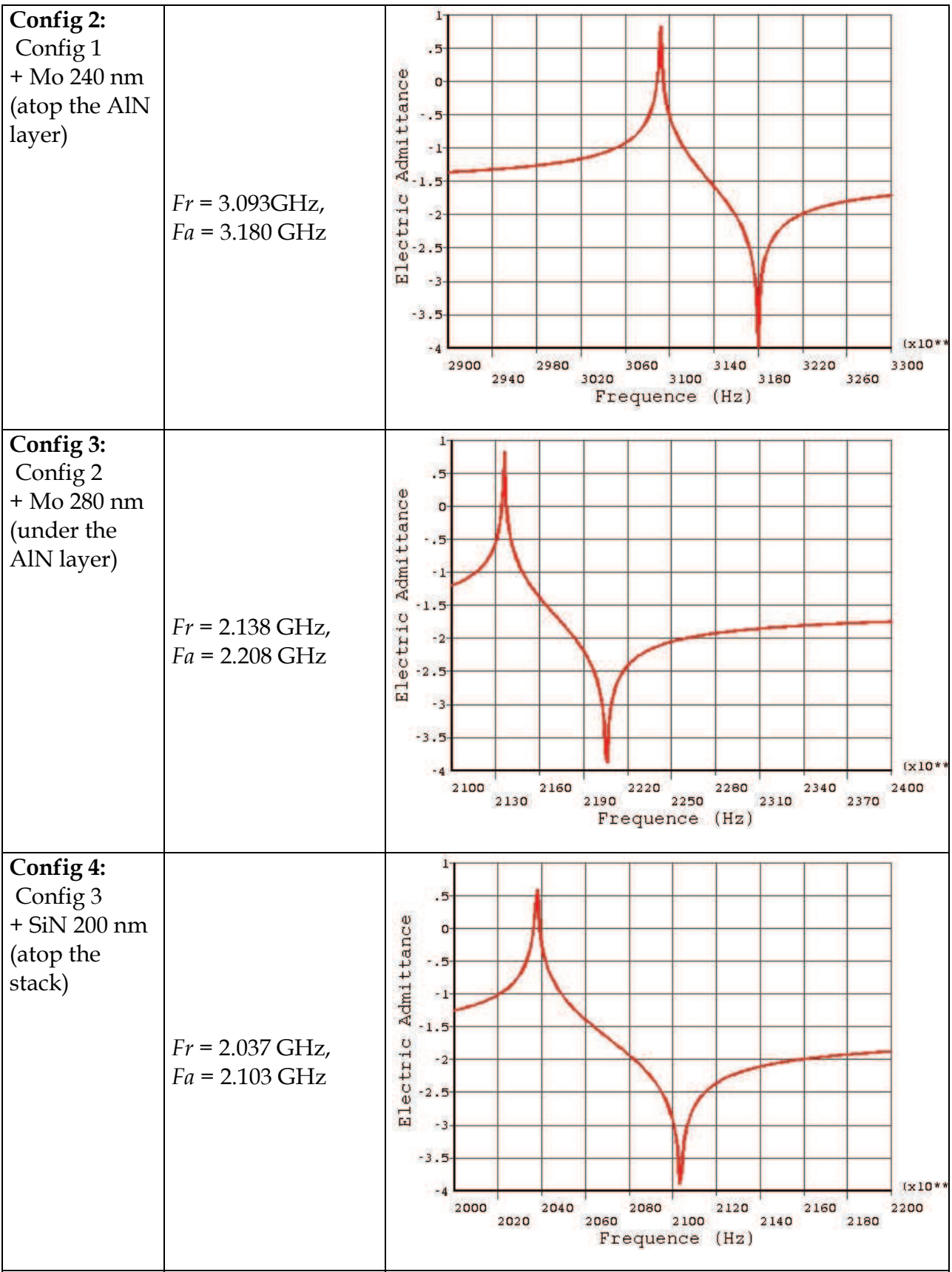




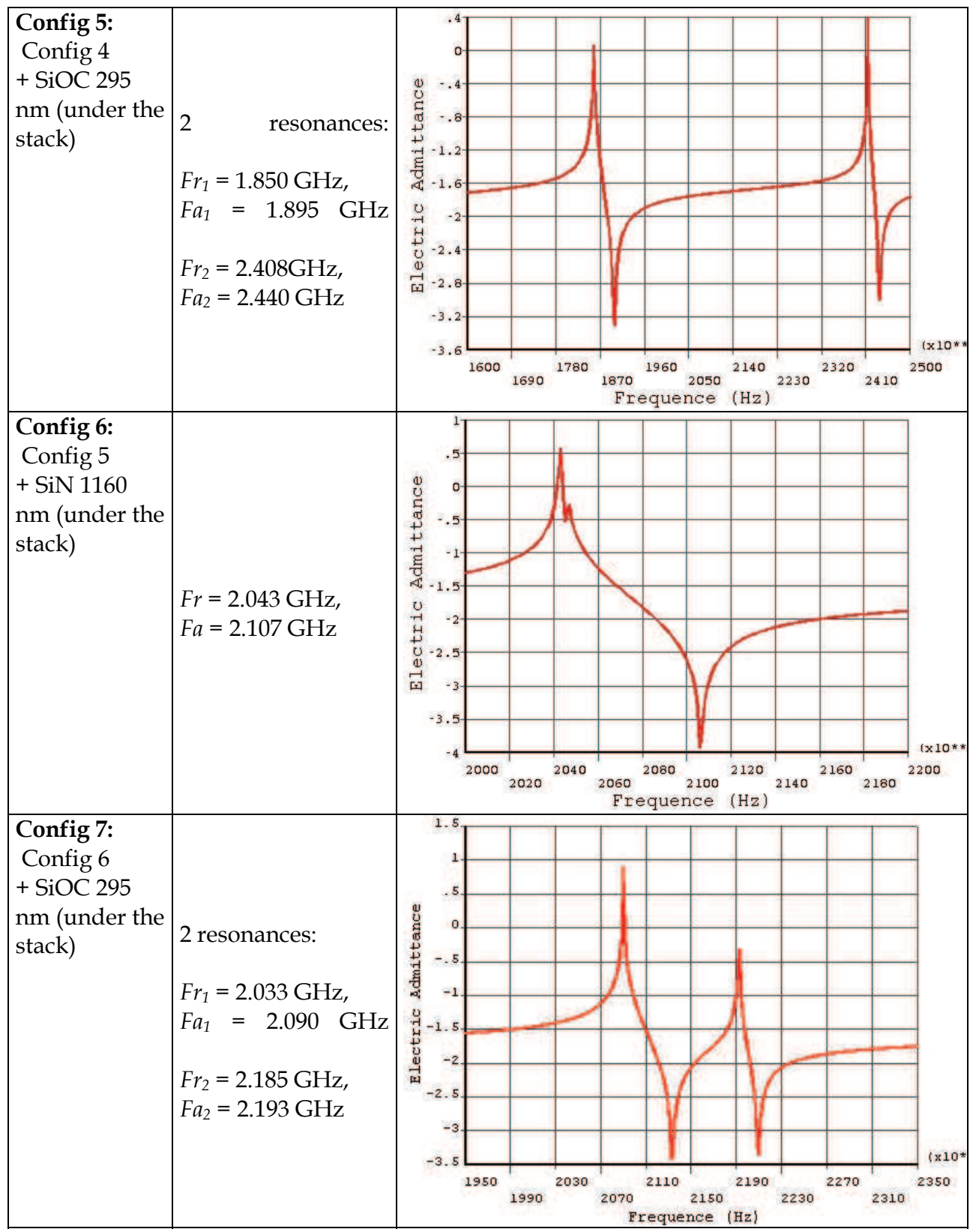




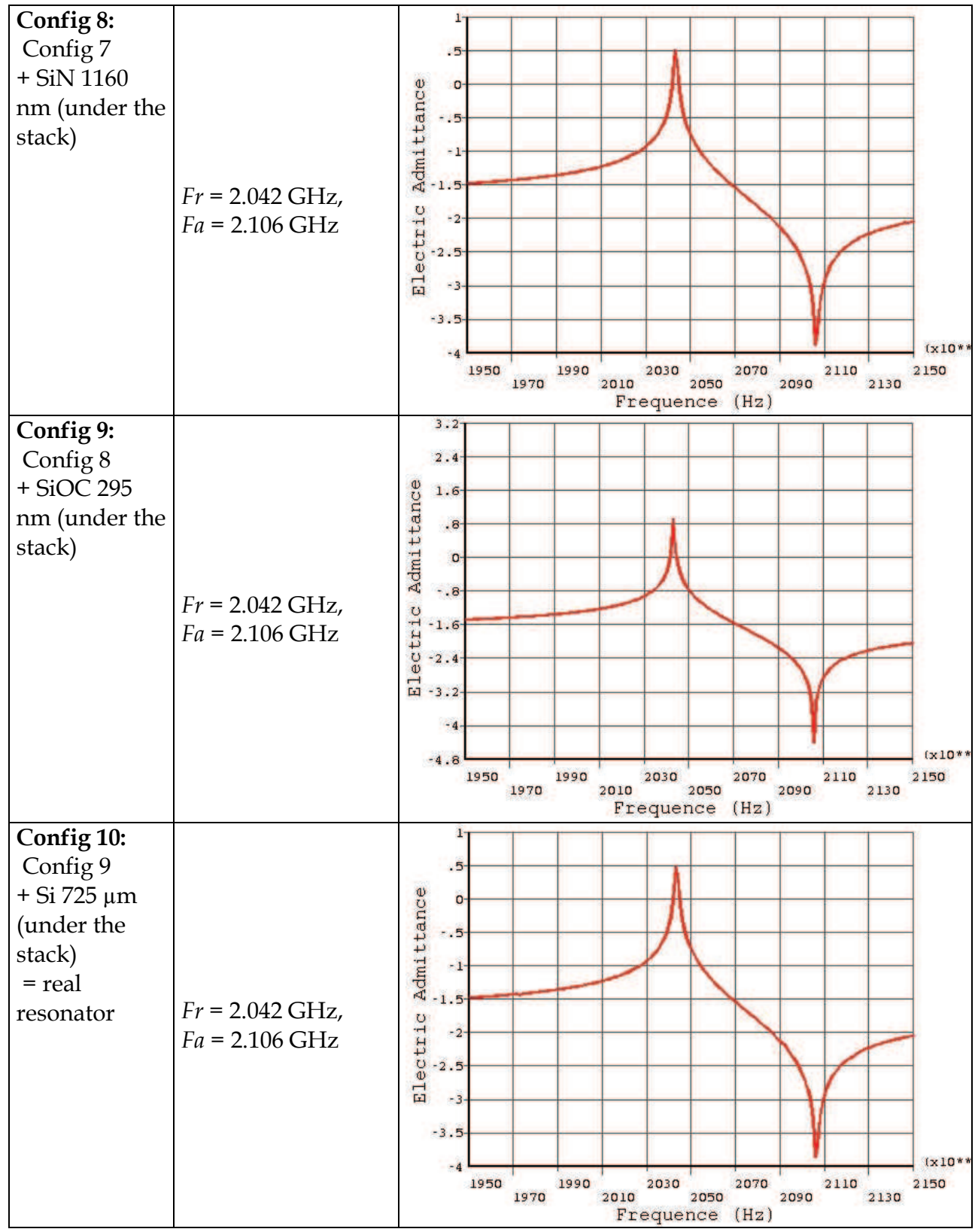

A good agreement between ANSYS numerical results and the analytical Mason multilayer model (Rosenbaum, 1988; Christopoulos, 1995) has been observed. 


\subsection{D numerical simulation of a BAW resonator structure}

Only a quarter of the resonator structure (as is it seen in transversal plane) has been taken into account in order to reduce the computational FEM effort required by 3D FEM simulations of the whole stack (Fig. 16. (a),(b)). Mechanical boundary conditions (zero displacement constraints for transversal directions, $u x=0$ or $u y=0$ ) and $d V / d n=0$ boundary condition (for piezoelectric layer) are imposed on the symmetry planes. The mesh discretization for longitudinal directions is the same as in previous chapter. For lateral directions we used a discretization of ndiv x ndiv 20-node brick elements.

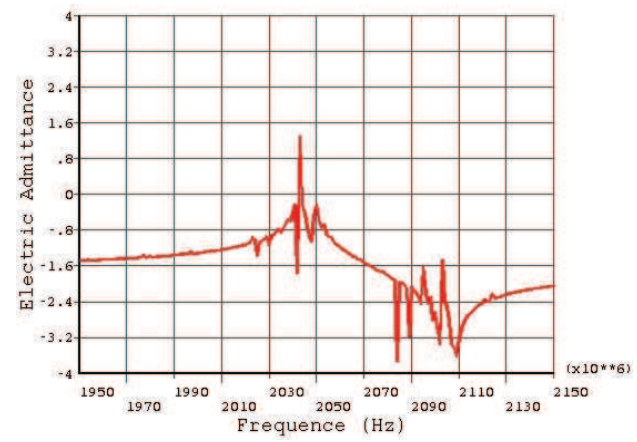

(a) Lateral boundaries are free

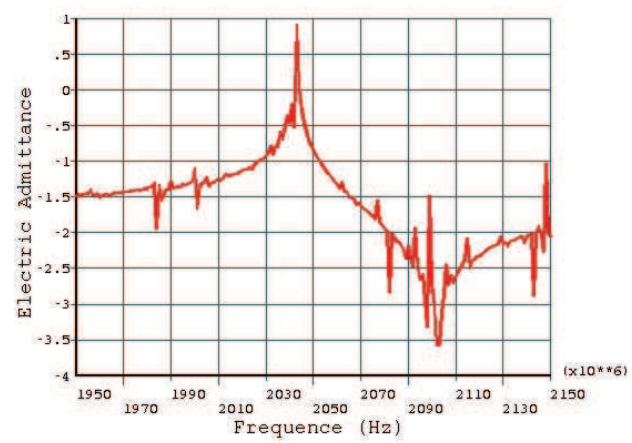

(b) Lateral boundaries have zero displacement constraints for all directions

Figure 16. 3D simulations ( $n$ div $=8$ )

In order to establish a more realistic model for transversal wave propagation we extend all layers by ext $\mu \mathrm{m}$ in each lateral side (because the abrupt end of the mesh is far from the real structure). For this new volume the mesh is much less dense. The electrodes have the area of $1 / 4 \times 22500 \mu \mathrm{m}^{2}$. Some results obtained using this approach are presented in Fig. 17 and Fig. 18. Obviously, the results taking into account a larger extended part are closer to the real structure. 


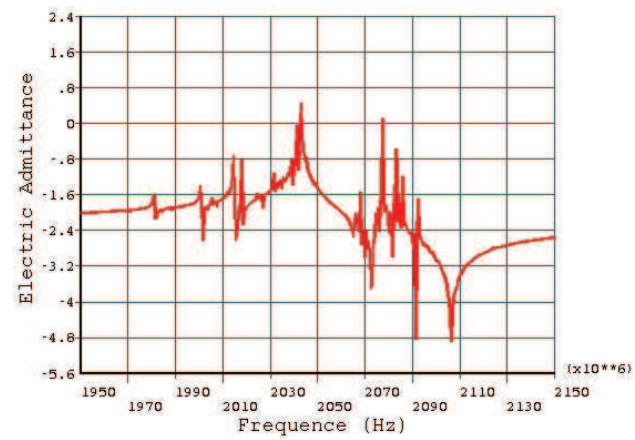

(a) Lateral boundaries are free

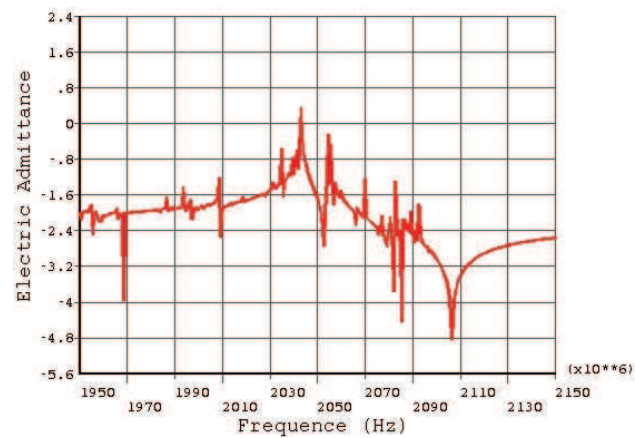

(b) Lateral boundaries have zero displacement constraints for all directions

Figure 17. 3D simulations for lateral extended stack ( $n d i v=6$ and 2 divisions for lateral extended side with ext $=100 \mu \mathrm{m}$ )

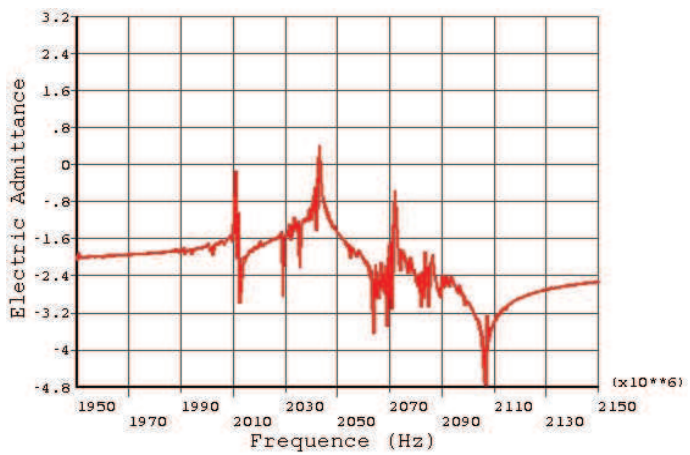

Figure 18. 3D simulations for lateral extended stack (ndiv $=8$ and 4 divisions for lateral extended side with $e x t=200 \mu \mathrm{m}$, lateral boundaries have zero displacement constraints for all directions.)

The local stress values are shown in Fig. 19. According to common expectations, the maximum values are obtained for the series resonance frequency. 


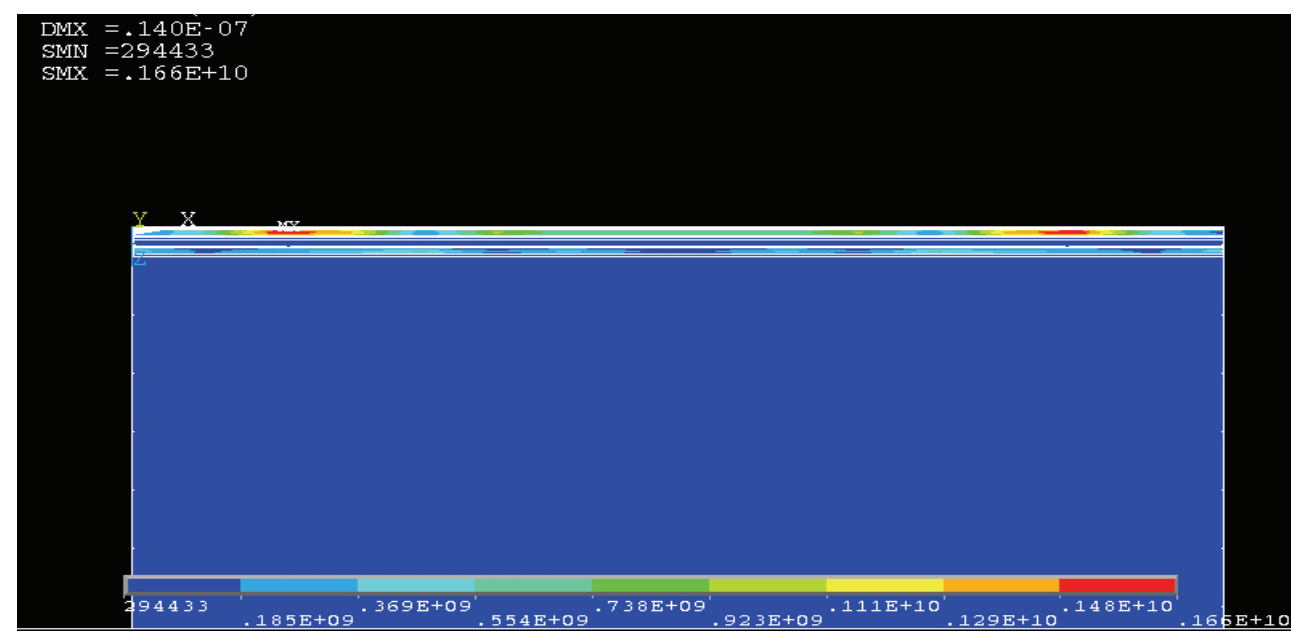

Figure 19. Local stress

Remarks:

- $\quad$ The resonance frequencies corresponding to longitudinal propagation are the same for all models.

- The lateral modes are more accentuated and unstable. Some possible causes:

- Model assumptions which are not satisfied by the real structure

a. Thickness uniformity

b. Approximate layer lateral dimensions

c. Approximate lateral boundary condition (mechanical)

- $\quad$ Ill- conditioned meshing (in order to save CPU time, a small number of lateral divisions has been considered)

- Approximate material parameters (not measured)

a. Some AlN parameters on transversal directions are taken from literature (where different values are given)

b. All layers, except AIN, are considered isotropic (perhaps they are not); the parameters on lateral directions being considered equal to that on the longitudinal direction.

\section{Circuit models for power BAW resonators and filters}

As BAW resonators are used to build filters which are parts of intricate circuits, like the power amplifier and duplexer in the mobile phone, circuit models are very useful in the design at system level. At a relatively low incident power the BAW resonator has a linear behaviour which can be described in a broad frequency range by the Mason model (Wilson, 1989), a circuit which contains lumped and distributed parameter elements. In the vicinity of a resonance frequency pair (as, for example corresponding to the thickness mode) a simpler model, the Butterworth-Van Dyke (BVD) circuit, can be used (Fig. 20). 


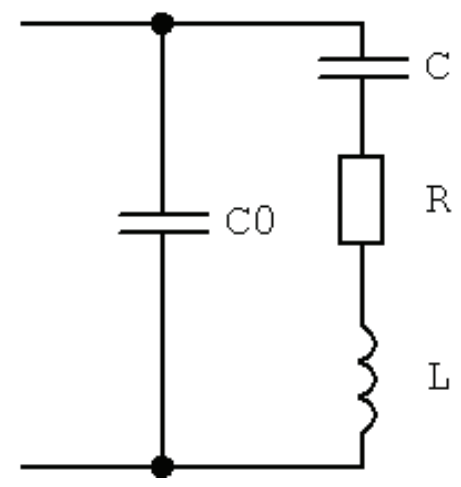

Figure 20. Butterworth-Van Dyke circuit

A high power fed into the BAW resonator produces three nonlinear effects, namely: the amplitude-frequency effect, the intermodulation effect, and the bias-frequency effect (Nosek, 1999; Aigner et al., 2005).

The amplitude-frequency effect is illustrated by the series resonance frequency increase as excitation amplitude increases for a quartz resonator (Fig. 21) (Nosek, 1999). A decrease of the series resonance frequency as the excitation amplitude increases has been observed in the case of an AlN stack crystal filter (Ketcham et al., 1988). The intermodulation effect consists, for example, in measuring some harmonic components of the response to a sinusoidal excitation (Nosek, 1999; Aigner et al., 2005; Ketcham et al., 1988). The shift of the series resonance frequency as a function of bias voltage is the bias-frequency effect (Aigner et al., 2005).

The linear parametric model in Fig. 22, valid for the response on the fundamental frequency, which is able to reproduce this amplitude-frequency effect, is described in (Nosek, 1999). The resistance and the capacitance in the motional branch of the BVD circuit are considered as dependent on the r.m.s. current value $I$ in this branch:

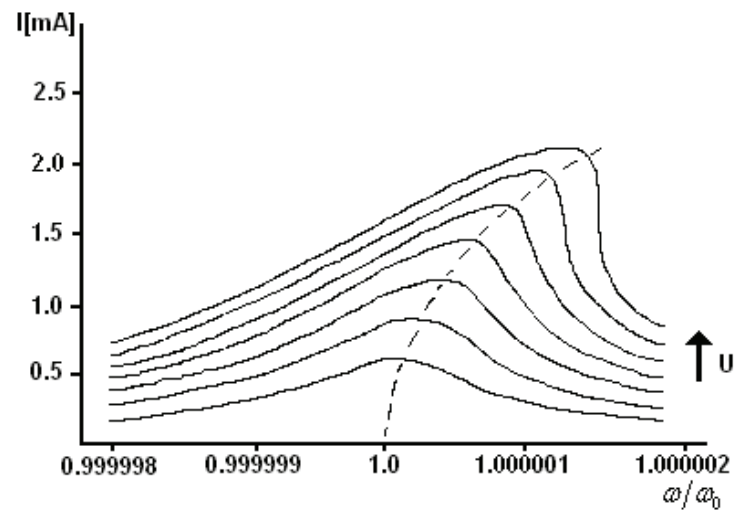

Figure 21. Frequency characteristics of a quartz resonator (I- resonator current, U- excitation voltage) 


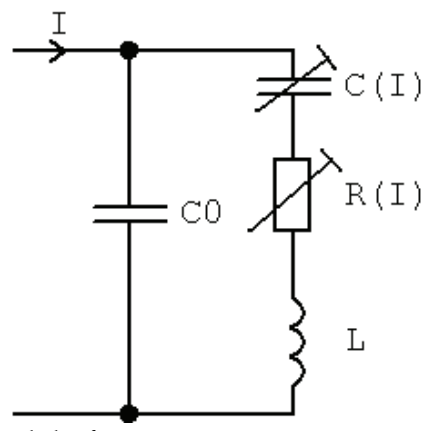

Figure 22. Linear parametric model of a quartz resonator

$$
R(I)=R\left(1+\beta I^{2}\right) \quad \frac{1}{C(I)}=\frac{1}{C}\left(1+\alpha I^{2}\right) .
$$

This linear parametric model and other similar ones (Constantinescu et al., 2007) can reproduce the amplitude-frequency effect but don't give intermodulation products.

These linear models contain parametric circuit elements whose characteristics depend on a r.m.s. value. This kind of dependence is not allowed in circuit simulators working in the frequency domain as ADS and APLAC (Constantinescu et al., 2007). Moreover, it cannot be used in a circuit simulator working in the time domain as SPICE or SPECTRE (Constantinescu et al., 2007). To overcome this difficulty, iterative AC analyses have been implemented in APLAC and MAPLE (Constantinescu et al., 2007). Even though these methods can lead to correct results in a reasonable amount of time for the analysis of a circuit composed by several resonators, they cannot be used for the analysis of an intricate system like the power amplifier and duplexer in a mobile phone.

Starting from an idea in (Aigner et al., 2005) two new nonlinear circuit models have been developed (Constantinescu et al., 2007). The first model is based on the BVD circuit in which the nonlinear resistor, inductor and capacitor are implemented as nonlinear controlled sources (Fig. 23).

The following parameter values were used for the APLAC implementation of this circuit: $\mathrm{C} 0=1.566 e-12$

CCVS R1 $112011 \quad b \quad\left[4.695^{*}\left(\mathrm{CI}(0)+0.5^{*} \mathrm{CI}(0)^{\wedge} 2+0.5^{*} \mathrm{CI}(0)^{\wedge} 3\right)\right] \mathrm{R}$

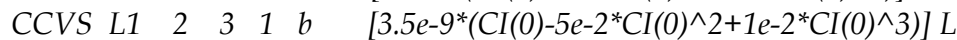

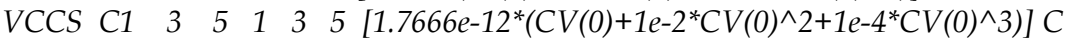

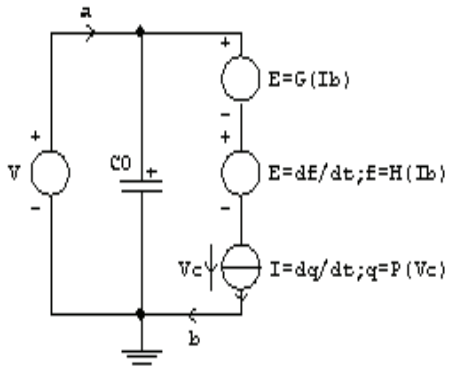

Figure 23. Controlled source implementation of the first nonlinear circuit model 
The amplitude-frequency effect of this model is shown in Fig. 24, where the frequency characteristics for the $1 \mathrm{~V}, 3 \mathrm{~V}$, and $5 \mathrm{~V}$ excitation amplitude are given. The decreasing of the series resonance frequency as the excitation amplitude increases may be observed. The second and third harmonic amplitudes obtained with the first model are given in Fig. 25 for three excitation frequencies.

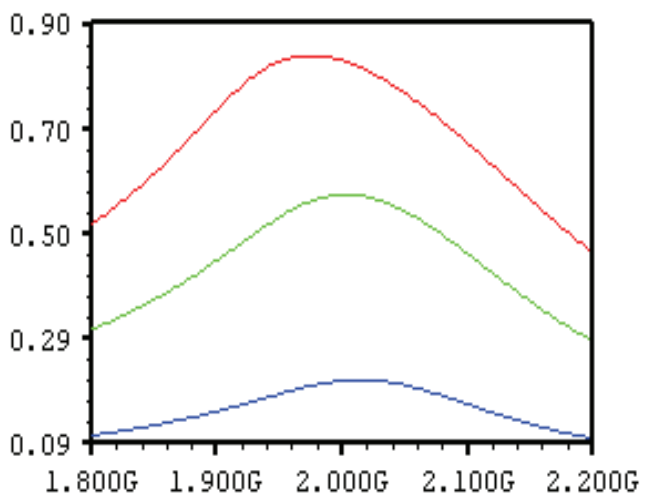

Figure 24. Ia vs. frequency for the first nonlinear model

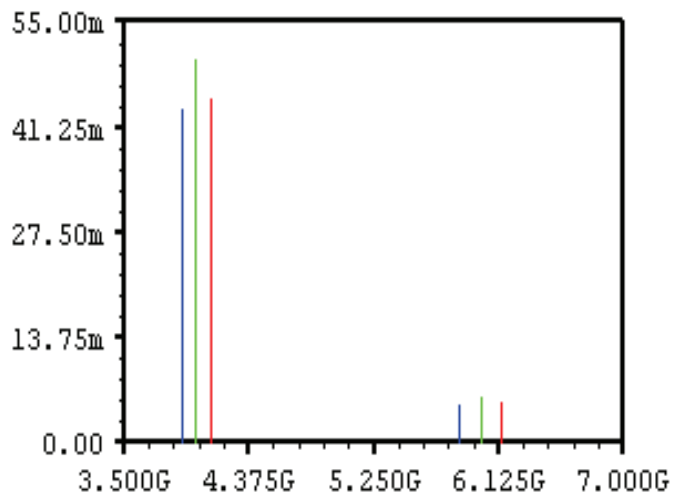

Figure 25. Intermodulation products for $\mathrm{V}=5 \mathrm{~V}$, first model

Forcing the current value in the motional branch by means of the VCCS, the capacitor has a dominant role in this model, both the resonance frequency shift and the amplitudes of the intermodulation products depending mainly on its nonlinear characteristic. To avoid this disadvantage a second model is proposed (Fig. 26). 


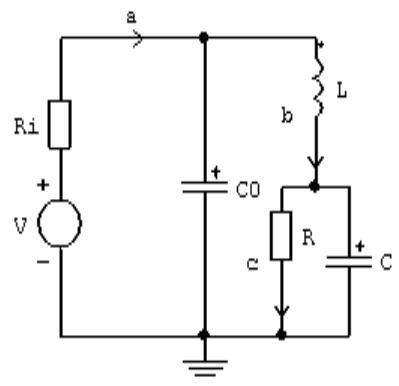

Figure 26. Second nonlinear circuit model

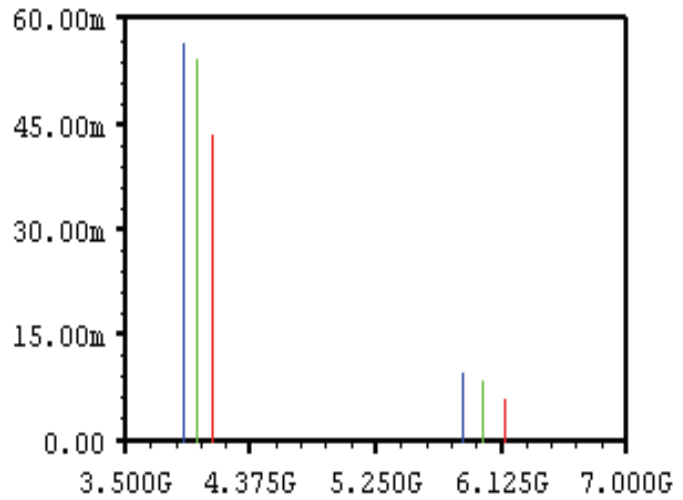

Figure 27. Intermodulation products for $\mathrm{V}=5 \mathrm{~V}$, second model

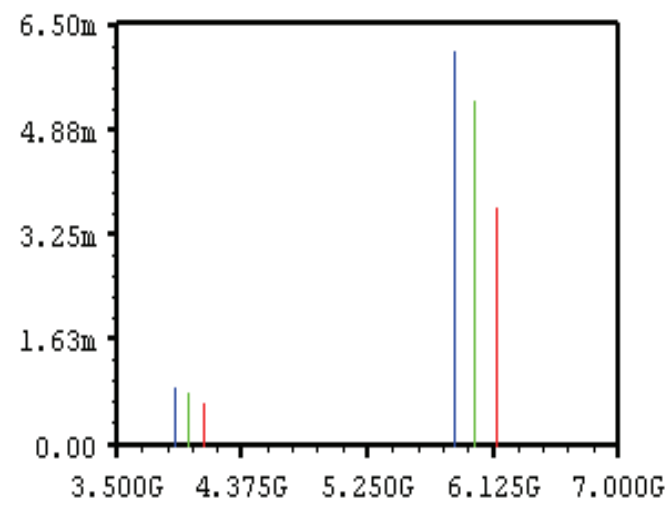

Figure 28. Intermodulation products, second model with modified inductor 
The following parameter values were used for the APLAC implementation of this circuit: $\mathrm{C} 0=1.566 \mathrm{e}-12$

CCVS L1 $121 b\left[3.5 e-9^{*}\left(\mathrm{CI}(0)+.1^{*} \mathrm{CI}(0)^{\wedge} 2+1 e-2 * \mathrm{CI}(0)^{\wedge} 3\right)\right] \mathrm{L}$

CCVS R1 351 c $\left[430^{*}\left(\mathrm{CI}(0)+2 e-2^{*} \mathrm{CI}(0)^{\wedge} 2+2 e-2 * \mathrm{CI}(0)^{\wedge} 3\right)\right] \mathrm{R}$

VCCS C1 3 GND 13 GND [.177e- $\left.12^{*}\left(C V(0)+5 e-5 * C V(0)^{\wedge} 2+5 e-5 * C V(0)^{\wedge} 3\right)\right] C$

This circuit shows an amplitude-frequency effect similar to the first model. Its intermodulation effect is illustrated in Fig. 27.

In order to show the better fitting properties of this second model, let's modify the inductance parameters as:

CCVS L1 $121 b$ [3.5e-9*(CI $\left.\left.(0)+\underline{1 e-3}{ }^{*} \mathrm{CI}(0)^{\wedge} 2+\underline{1 e-3}{ }^{*} \mathrm{CI}(0)^{\wedge} 3\right)\right] \mathrm{L}$

(changed values are underlined). Using this new inductance the amplitude-frequency effect remains the same, while the amplitude of the second harmonic practically vanishes as it is shown in Fig. 28.

The second circuit model allows a better control of both amplitude-frequency effect and intermodulation effect than the first one. This control is obtained by varying the coefficients of the polynomial nonlinearities. In order to validate these models, we considered the measured dependence of the series resonance frequency on the incident power (Constantinescu et al., 2008). A comparison between the simulated and measured data is given in Fig. 29.

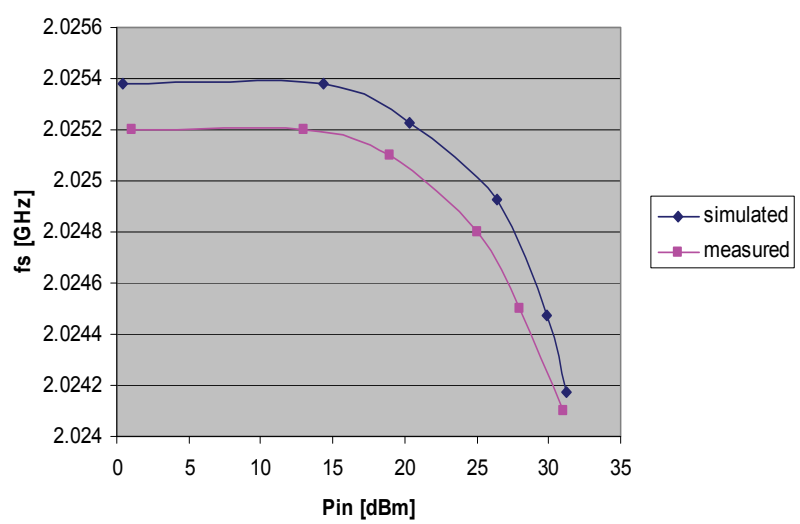

Figure 29. The dependence of the series resonance frequency on the incident power

In order to compare simulation results in time domain (TD) and frequency domain (FD) the two resonator filter in Fig. 30 has been analyzed both with periodic steady state analysis (PSS) and harmonic balance analysis of SPECTRE.

These analyses are implemented in the IC 6.1.0 package of CADENCE. The polynomial nonlinearities are defined by the coefficients a0, a1, a2, whose meaning has been shown before. The running options are:

SetOption1 options iabstol=1e-13 vabstol=1e-12 digits=8 fund=2.025G harms=4 outputtype=all errpreset $=$ conservative 


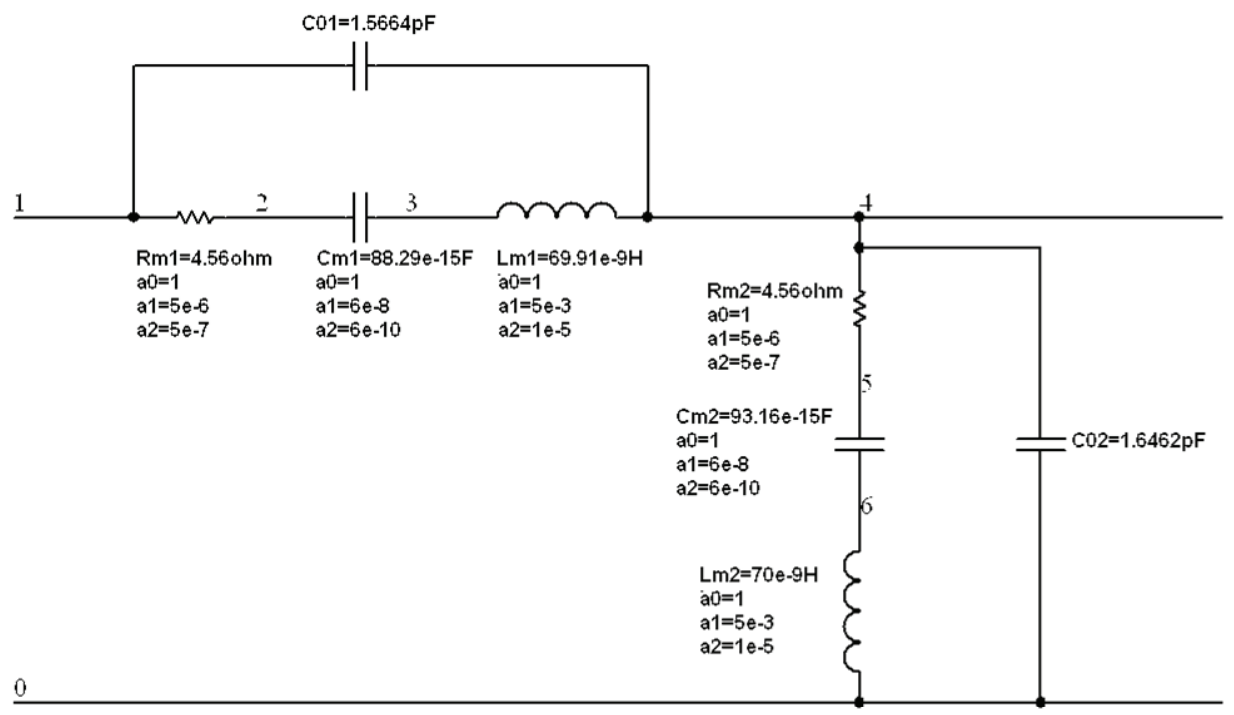

Figure 30. A nonlinear model of a two resonator power BAW filter

The harmonic components of the output signal are given in the following tables, for two values of the parameter "reltol".

\begin{tabular}{|l|l|l|}
\hline & TD & FD \\
\hline f component & $3.646 \mathrm{~V}$ & $3.646 \mathrm{~V}$ \\
\hline 2f component & $239 \mathrm{uV}$ & $239 \mathrm{uV}$ \\
\hline 3f component & $191.6 \mathrm{nV}$ & $118.8 \mathrm{nV}$ \\
\hline
\end{tabular}

Table 5. Harmonic components of the output signal, reltol=1e-6

\begin{tabular}{|l|l|l|}
\hline & TD & FD \\
\hline f component & $3.646 \mathrm{~V}$ & $3.646 \mathrm{~V}$ \\
\hline 2f component & $238.9 \mathrm{uV}$ & $239 \mathrm{uV}$ \\
\hline 3f component & $115.5 \mathrm{nV}$ & $118.8 \mathrm{nV}$ \\
\hline
\end{tabular}

Table 6. Harmonic components of the output signal, reltol=1e-9

These results show a very good agreement between the TD and FD analyses.

Further research will be devoted to filter modeling and simulation taking into account real RF signals (not sinusoidal ones as in the case of the results given before). To this end new nonlinear circuit models can be developed using simple impedance transformations.

\section{Acknowledgments}

The authors acknowledge the financial support of the FP6 project MOBILIS. 


\section{References}

Cady, W. G. (1964). Piezoelectricity. An Introduction to the Theory and Applications of Electromechanical Phenomena in Crystals, Dover Publ., Vols. I and II, , New York.

Wilson, O. B. (1989). Introduction to the theory and design of sonar transducers, Peninsula Publishing, ISBN: 978-0-9321-4622-9, Los Altos, California.

Hantila, F.I.; Preda, G. \& Vasiliu, M. (2000). Polarization Method for Static Fields, IEEE Transaction on Magnetics, Vol.36, No.4, Jul 2000, pp. 672-675, ISSN: 0018-9464.

Makkonen, T.; Holappa, A.; Ella, J. \& Salomaa, M. (2001), Finite Element Simulations of Thin-Film Composite BAW Resonators, IEEE Transactions on Ultrasonics, Ferroelectrics, and Frequency Control, Vol.48, No.5, Sep 2001, pp. 1241-1257, ISSN: 0885-3010.

Makkonen, T. (2005). Numerical Simulations of Microacoustic Resonators and Filters, Doctoral Dissertation, Helsinki University of Technology, apr. 2005, ISBN 9512276364, pp. $1-75$.

Ostergaard, D. F. \& Pawlak, T. P. (1986). Three-Dimensional Finite Elements for Analyzing Piezoelectric Structures, 1986 IEEE Ultrasonics Symposium, pp. 639-644.

Popovici, D.; Păltânea, V.; Păltânea, G. \& Jiga, G. (2006). Determination of the stress and strain state in metallic structures using piezoelectrical transducers, Proceedings of the COMSOL Users Conference, 2006, Prague.

*** (2005). COMSOL 3.2., Structural Mechanics, Manual, Comsol, AB, Sweden.

*** (2005). ANSYS, Inc., Release 10.0 Documentation for ANSYS, online documentation, documentation $\mathrm{CD}$.

Rosenbaum, J. F. (1988). Bulk Acoustic Waves Theory and Devices, Artech House, Boston.

Christopoulos, C. (1995). The Transmission-Line Modeling Method: Tlm, IEEE Computer Society Press, ISBN: 978-0-7803-1017-9.

Nosek, J. (1999). Drive level dependence of the resonant frequency in BAW quartz resonator and his modeling, IEEE Transactions on Ultrasonics, Ferroelectrics, and Frequency Control, Vol.46, No.4, Jul 1999, pp. 823-829, ISSN: 0885-3010.

Aigner, R.; Huynh, N.-H.; Handtmannn, M. \& Markensteiner, S. (2005). Behavior of BAW devices at high power levels, Proceedings of IEEE IMS-MTT-S 2005, Long Beach.

Ketcham, R. S.; Kline, G. R. \& Lakin, K. M. (1988). Performance of TFR filters under elevated power conditions, 42-nd Annual Frequency Control Symposium, pp. 106-111, USA, 1-3 Jun 1988, Baltimore.

Constantinescu, F.; Nitescu, M. \& Gheorghe, A. G. (2007). Circuit Models for Power BAW Resonators - Set-up and Implementation, Proceedings of AFRICON 2007, pp. 1-6, ISBN: 978-1-4244-0987-7, Namibia, 26-28 Sept., 2007, Windhoek.

Constantinescu, F.; Nitescu, M. \& Gheorghe, A. G. (2008). New Nonlinear Circuit Models for Power BAW Resonators, IEEE International Conference on Circuits and Systems for Communications, Shanghai, China, May 26-28, 2008. 


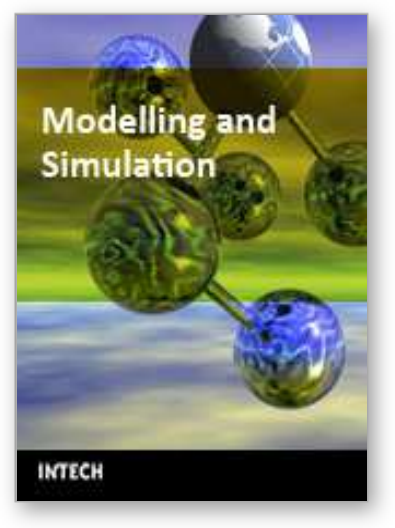

\author{
Modelling and Simulation \\ Edited by Giuseppe Petrone and Giuliano Cammarata
}

ISBN 978-3-902613-25-7

Hard cover, 688 pages

Publisher I-Tech Education and Publishing

Published online 01, June, 2008

Published in print edition June, 2008

This book collects original and innovative research studies concerning modeling and simulation of physical systems in a very wide range of applications, encompassing micro-electro-mechanical systems, measurement instrumentations, catalytic reactors, biomechanical applications, biological and chemical sensors, magnetosensitive materials, silicon photonic devices, electronic devices, optical fibers, electro-microfluidic systems, composite materials, fuel cells, indoor air-conditioning systems, active magnetic levitation systems and more. Some of the most recent numerical techniques, as well as some of the software among the most accurate and sophisticated in treating complex systems, are applied in order to exhaustively contribute in knowledge advances.

\title{
How to reference
}

In order to correctly reference this scholarly work, feel free to copy and paste the following:

Dorina Popovici, Florin Constantinescu, Mihai Maricaru, Florea Ioan Hantila, Miruna Nitescu and Alexandru Gheorghe (2008). Modeling and Simulation of Piezoelectric Devices, Modelling and Simulation, Giuseppe Petrone and Giuliano Cammarata (Ed.), ISBN: 978-3-902613-25-7, InTech, Available from: http://www.intechopen.com/books/modelling_and_simulation/modeling_and_simulation_of_piezoelectric_devic es

\section{INTECH}

open science | open minds

\author{
InTech Europe \\ University Campus STeP Ri \\ Slavka Krautzeka 83/A \\ 51000 Rijeka, Croatia \\ Phone: +385 (51) 770447 \\ Fax: +385 (51) 686166 \\ www.intechopen.com
}

\author{
InTech China \\ Unit 405, Office Block, Hotel Equatorial Shanghai \\ No.65, Yan An Road (West), Shanghai, 200040, China \\ 中国上海市延安西路65号上海国际贵都大饭店办公楼405单元 \\ Phone: +86-21-62489820 \\ Fax: +86-21-62489821
}


(C) 2008 The Author(s). Licensee IntechOpen. This chapter is distributed under the terms of the Creative Commons Attribution-NonCommercialShareAlike-3.0 License, which permits use, distribution and reproduction for non-commercial purposes, provided the original is properly cited and derivative works building on this content are distributed under the same license. 